\title{
Turning low-cost recycled paper into high- value binder-free all-cellulose panel products
}

Raquel Arévalo

School of Engineering and Materials Science and Materials Research Institute, Queen Mary University of London, London, UK

Nattakan Soykeabkaew

Center of Innovative Materials for Sustainability (iMatS), School of Science, Mae Fah Luang University, Chiang Rai, Thailand
Ton Peijs

Materials Engineering Centre, WMG, University of Warwick, Coventry, UK (corresponding author: t.peijs@warwick.ac.uk)

In this work, the feasibility of producing low-cost, recyclable and biodegradable binderless all-cellulose fibreboards was demonstrated through the successful manufacturing of self-binding composites based on recycled paper and kraft fibres. These all-cellulose composites were made by a simple and environmentally friendly solvent-free mechanical fibrillation method using water as a processing aid. Kraft fibres and recycled paper pulp were mixed in a $30 / 70 \mathrm{w} / \mathrm{w}$ ratio and refined simultaneously in a Valley beater for different periods of time. The mechanical properties of the composites, consisting of a 'matrix' of recycled paper reinforced with kraft fibres, were highly dependent on the level of fibrillation of the kraft fibres. Optimal levels of fibrillation resulted in a good balance of self-binding properties and reinforcing efficiency. The hot-pressed all-cellulose panels exhibited a flexural strength of $75 \mathrm{MPa}$ and a modulus of $5.9 \mathrm{GPa}$, which are impressive values compared with those of conventional fibreboard materials. In addition, these panels showed better water resistance than some existing wood panel products. These binder-free all-cellulose composites have potential as cost-effective sustainable alternatives to existing panel board products, as they are entirely made from renewable and recycled materials, which at the end of life can potentially be recycled or composted, making them perfectly fit for a circular economy.

\section{Notation}

$P \quad$ pressure

$T$ temperature

$t \quad$ time

$W_{\mathrm{d}} \quad$ weight of the dry sample

$W_{\mathrm{w}} \quad$ weight of the wet sample

$\rho_{\mathrm{c}} \quad$ density of cellulose

$\rho_{\mathrm{p}} \quad$ density of the panel

${ }^{\circ} \mathrm{SR} \quad$ Schopper-Riegler degree

\section{Introduction}

The early idea of green composite materials started with the use of natural fibres to replace glass fibres as a reinforcement for polymeric resins. ${ }^{1,2}$ These materials were of interest since they originate from a renewable resource, are biodegradable and lightweight and exhibit good specific strength and stiffness; they can also be incinerated with high energy recovery. However, a notable feature of lignocellulosic fibres is their hydrophilicity, which makes them compatible with hydrophilic polymers but mostly incompatible with hydrophobic polymer matrices, such as polypropylene. ${ }^{3}$ This issue leads directly to poor fibre-matrix adhesion and promotes void formation, which are both major strength-reducing factors in natural fibre composites. ${ }^{3,4}$ One of the potential solutions to enhancing fibre-matrix adhesion in cellulose-based composites, while at the same time creating a green material, is through the development of self-reinforced or all-cellulose composites. ${ }^{2,5,6}$

Prior works in the area of all-cellulose-based composites generally involved the use of solvents to dissolve the cellulose fibre surface selectively to form a matrix phase and fuse the cellulose fibres together. $^{7-11}$ Despite the remarkable mechanical properties of these all-cellulose composites, with moduli up to $20 \mathrm{GPa}$ and tensile strengths in excess of $200 \mathrm{MPa}$, the need for solvents in their processing makes this solution not really an environmentally benign one. Moreover, the solvent exchange process allows only for the development of relatively thin two-dimensional sheet-like materials. Hence, there is a need for a green solvent-free manufacturing process for all-cellulose composites, which allows for the possibility of creating thicker panel board products.

The recent years have seen a growing interest in producing binder-free or binderless fibreboards and composites made from different sources of lignocellulosic materials, as they can have both environmental and economic benefits. Binder-free fibreboards can provide fully recyclable, biodegradable and renewable green products while requiring no synthetic resins, binders or solvents in the production process. Moreover, as the physical properties of these materials make use of the self-binding capacity of nanocellulose networks through van der Waals interactions and/or hydrogen bonds as in paper, these materials are in principle recyclable similarly as paper. This makes these materials fit for a circular economy, in which it is aimed to minimise waste and make the most of resources by recovering and recycling products at the end of their life.

The optimisation of the self-binding capacity of cellulose networks relies on increasing the surface area of the cellulose fibres through micro- or nanofibrillation. Bacterial cellulose $\mathrm{s}^{12,13}$ and cellulose 
nanopaper, ${ }^{2,14}$ consisting of either cellulose nanofibres directly obtained from bacteria or cellulose nanofibres extracted from wood, are prime examples of self-binding cellulose materials. Initially, most research into cellulose networks was devoted to thin films and nanopaper exhibiting impressive tensile strength values of around $250 \mathrm{MPa}$. However, in recent years, more studies have been aimed at developing construction materials such as panel board products based on self-binding nanocellulose. For example, with the refinement of lignocellulosic materials, such as flax, into selfbinding nanofibrillated cellulose, the authors recently showed that the strength of such binderless all-cellulose panels can be raised to $120 \mathrm{MPa}$ with moduli of up to $17 \mathrm{GPa}^{15}$ These mechanical properties are quite impressive and outperform those of most conventional natural-fibre-reinforced plastics (NFRPs) or wood fibre panel products. ${ }^{15-17}$ However, the use of natural fibres, such as flax and hemp, for the manufacturing of these products at the industrial scale could pose problems related to their availability, storage and particularly price. More recently, cellulose nanofibre boards made from fibrillated softwood with a nominal thickness of $3 \mathrm{~mm}$ were prepared by using a press apparatus to dewater the cellulose nanofibre network prior to drying. ${ }^{18}$ The maximum flexural and tensile strengths of these cellulose nanofibre boards were 162 and $85 \mathrm{MPa}$, respectively.

The uses of flax fibres, ${ }^{15}$ cotton stalks, ${ }^{16}$ hardwood and softwood pulps, ${ }^{17}$ softwood sawdust, ${ }^{19}$ kraft $\operatorname{lignin}^{20}$ and banana bunch ${ }^{21}$ as raw materials to prepare binder-free all-cellulose panels have all been demonstrated. From these studies, many processing parameters have been identified as crucial for mechanical and physical properties of such materials, including pretreatment and refinement of the raw biomass materials and pressing and drying conditions of the moulded panels. The strength and modulus values of such binder-free cellulose panels are typically around 20-30 MPa and 2-4 GPa, respectively. ${ }^{17,19-21}$ More recently, with the self-binding potential of nanocellulose recognised, a number of studies have shown its use as a sustainable adhesive replacement in paper, fibreboard, formaldehyde-free hybrid composites and woodbased panels. ${ }^{22-26}$ For instance, a laminate system composed of stacked sheets of paper impregnated with cellulose nanofibrils was pressed and bonded together. It was found that the flexural modulus and strength of these composite laminates were as high as $3.6 \mathrm{GPa}$ and $39 \mathrm{MPa}$, respectively. ${ }^{27}$ In another approach, a nanocomposite laminate was produced by dipping strips of paper in a cellulose nanofibril suspension, cross-folding the soaked strips into a wet laminate and hot-pressing it in a hydraulic press to obtain a stiff laminate. This laminated paper sample showed a flexural strength of around $100 \mathrm{MPa}$ and a flexural modulus of $8 \mathrm{GPa}^{28}$ Interestingly, the mechanical performance of this laminate exceeded that of short glass- or natural-fibre-reinforced plastics, as well as that of some wood fibre panel boards.

To endorse a circular economy further, the use of alternative cellulose sources from waste streams such as recycled paper could prove an interesting cost-effective alternative for binderless allcellulose composites due to their relatively low cost and availability throughout the year, thus eliminating possible problems associated with storage. However, it is well known that recycled paper fibres present inferior strength properties and lower bonding capability compared with virgin or freshly pulped fibres as a consequence of chemical and physical changes undergone during pressing, drying, printing, storage, re-pulping and de-inking. ${ }^{29}$ Most of the changes that reduce the strength properties of recycled paper fibres arise from the drying process since it brings about partially irreversible closure of small pores in the fibre wall, as well as an increased resistance to swelling during rewetting. ${ }^{30}$ The phenomenon associated with this partially irreversible loss of flexibility and swelling capacity of fibres after drying is known as hornification. Hornification occurs when hydrogen bonds formed between cellulose chains in the cell wall during drying cannot be broken during the rewetting process, resulting in only partial swelling since some chains remain bonded. ${ }^{31,32}$ The loss of the swelling capability of recycled paper fibres leads to reduced fibre flexibility, less fibre-fibre contacts and therefore reduced inter-fibre network bonding. ${ }^{33}$ Therefore, drying conditions affect cellulose fibre strength, fibre swelling and binding potential. ${ }^{34}$ Intrinsic fibre strength, inter-fibre bonding and inter-fibre contacts are all known parameters that affect the mechanical properties of fibrous cellulose networks. ${ }^{35-37}$ Different approaches can be followed for the recovery of the binding potential of recycled fibres including rerefining and blending with virgin fibre pulps. ${ }^{38}$

In an attempt to produce binder-free all-cellulose composites at a reduced cost compared with those reported by the authors previously, ${ }^{15,39}$ the use of highly fibrillated recycled paper fibres as a raw material was explored in this work. Due to the lower strength and bonding capability of these recycled paper fibres compared with those of lignocellulosic fibres such as flax and hemp, bleached kraft fibres were incorporated in the recycled paper pulp matrix with the aim of enhancing their overall mechanical performance. The reinforcing effect of fibrillated kraft fibres in the recycled paper matrix was studied as a function of refinement time. After dewatering and hot-pressing, the mechanical properties and water absorption (WA) behaviour of the resulting binderless kraft fibre/recycled paper composite panels were assessed.

\section{Experimental section}

\subsection{Materials and characterisation}

In this work, recycled paper pulp was used for the production of binder-free all-cellulose composite panels. This de-inked recycled wet paper pulp was kindly provided in 251 plastic containers by Drumparam (Austria). In order to improve the mechanical performance of these recycled paper materials, bleached kraft pulp was used as a reinforcement to create binderless kraft fibre/ recycled paper composites. Bleached kraft fibres with a fibre length between 2 and $3 \mathrm{~mm}$ were provided in sheet form ( $80 \times$ $80 \mathrm{~cm}$ ) by Norske Skog (Norway). Figure 1 shows images of the as-received recycled paper pulp (Figure 1(a)) and bleached kraft fibre sheet (Figure 1(b)). 


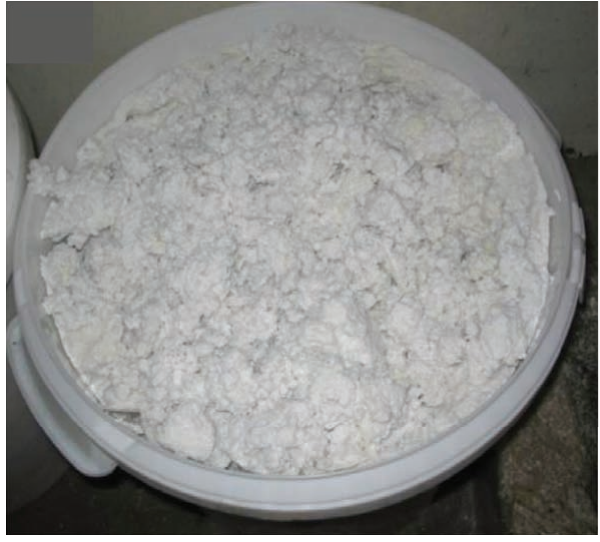

(a)

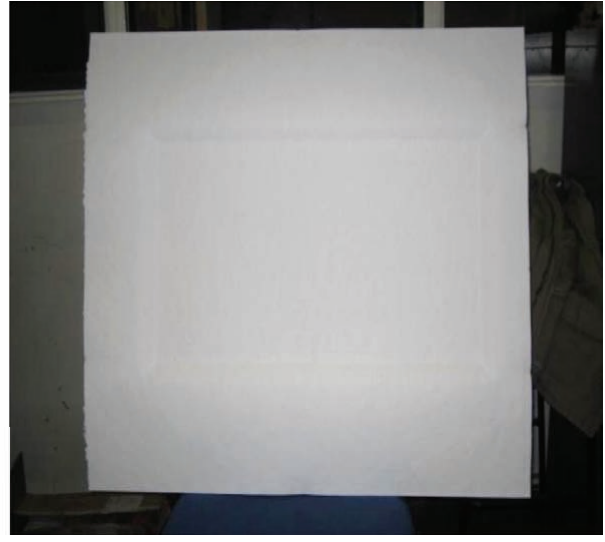

(b)

Figure 1. Images of (a) as-received recycled paper pulp in a 25 I plastic container and (b) bleached kraft fibre sheet $(80 \mathrm{~cm} \times 80 \mathrm{~cm})$

To improve inter-fibre binding between the recycled paper pulp matrix and the bleached kraft fibre, a high degree of microfibrillation of the cellulose fibres is required, as previously demonstrated in many works. ${ }^{15-17,19,20}$ Pieces of kraft paper were first soaked in water and disintegrated in a Valley beater for 15 min. After disintegration, the kraft fibres were refined in the Valley beater for different periods of time $(5,10,15,20,25$ and $30 \mathrm{~min})$. The level of microfibrillation was first indirectly evaluated by determining the drainability of the refined pulp suspensions through the Schopper-Riegler (SR) method. ${ }^{40}$ This test measures the rate of water drainage from the pulp fibres and gives an indication of the so-called freeness of the pulp and degree of fibrillation and hydration of the pulp fibres.

Figure 2 shows the SR apparatus employed for performing such tests together with a working schematic diagram. The functioning of this device is quite simple, as can be deduced from the schematic diagram. The technology is based on the principle that finer pulp suspensions are more hydrated, slowing down the water drainage through the filter and allowing most of the water to pass through orifice B. The small amount of water collected from orifice A indicates the SR degree ( $\left.{ }^{\circ} \mathrm{SR}\right)$ of the pulp in the collector vessel. Hence, the ${ }^{\circ} \mathrm{SR}$ value of high-fibrillated pulp will be higher than that of low-fibrillated pulp. For lightly beaten pulp suspensions, the water drainage through the filter is fast, and, consequently, water accumulates in the cone. In this case, most of the drained water will pass through orifice A instead of B, leading to a lower ${ }^{\circ} \mathrm{SR}$ value. Pulp suspensions of kraft fibres for SR testing were prepared and tested according to ISO standard $5267 .{ }^{41}$ At least five suspensions of each pulp were tested, and the ${ }^{\circ} \mathrm{SR}$ values were averaged. The morphology of the kraft fibres as a function of refinement time was also observed using an Olympus BX60 optical microscope.

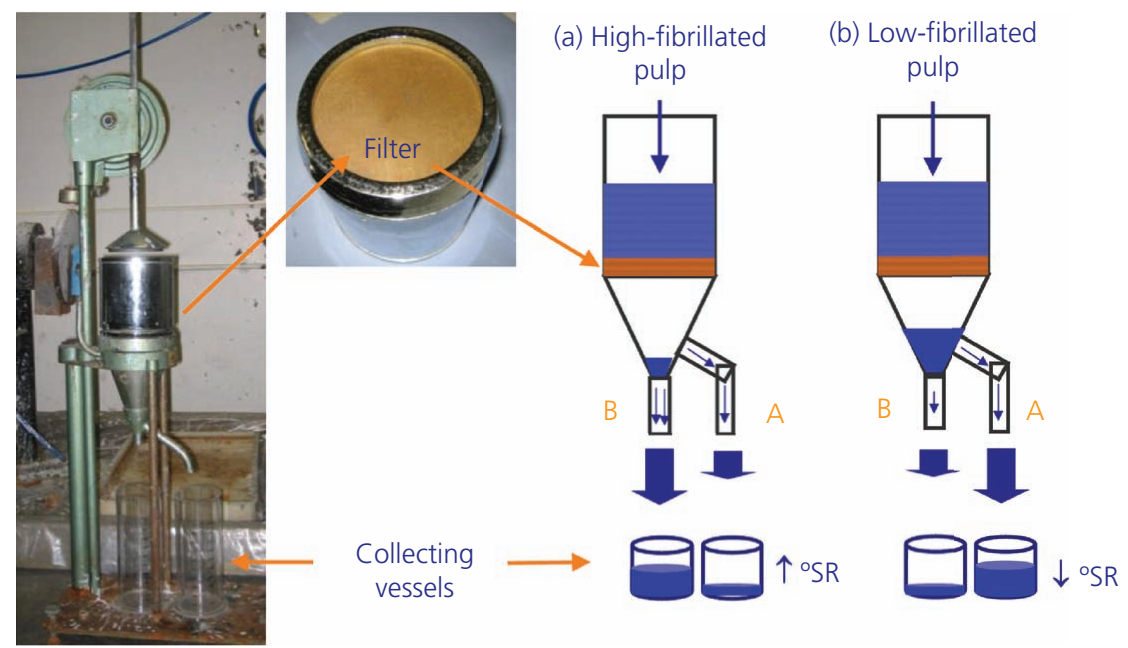

Figure 2. Image of the SR test set-up and working principle for the high-fibrillated pulp (a) and low-fibrillated pulp (b) 
Table 1. Hot-pressing conditions applied for the successful compaction and drying of recycled-paper-based composites

\begin{tabular}{lcl}
\multicolumn{3}{c}{ Hot-pressing parameters } \\
\hline Phase 1 & Phase 2 & Phase 3 \\
\hline$T=140^{\circ} \mathrm{C}$ & $T=140^{\circ} \mathrm{C}$ & $T=20^{\circ} \mathrm{C}$ \\
$P=20 \mathrm{bar}$ & $P=40 \mathrm{bar}$ & $P=40 \mathrm{bar}$ \\
$t=1200 \mathrm{~s}$ & $t=1200 \mathrm{~s}$ & $t=600 \mathrm{~s}$
\end{tabular}

$P$, pressure; $T$, temperature; $t$, time

\subsection{Preparation of binderless all-cellulose composite panels}

First, the kraft paper sheets were soaked in water and disintegrated in a Valley beater for $15 \mathrm{~min}$ prior to the addition of the recycled paper pulp. After disintegration, recycled paper was added to create a 30/70 w/w kraft fibre/recycled paper blend, which was refined in the Valley beater for different periods of time $(5,10,15,20,25$ and $30 \mathrm{~min}$ ), with the resulting blends used for the production of selfbinding all-cellulose composite panels. In this way, the effect of the degree of fibrillation of the kraft fibres and bonding of both types of fibres on the mechanical properties of the kraft fibre/recycled paper composites can be studied. To form binderless all-cellulose composite panels, after mixing and refining, the blended fibre pulp was subsequently filtered and pressed at room temperature for initial dewatering. Finally, this partially dewatered precursor cake was dried in a hot-press under conditions listed in Table 1. Hotpressing conditions for the kraft/recycled paper composites were based on the authors' previous work using microfibrillated flax fibres, ${ }^{20,35}$ albeit using a somewhat lower maximum pressure to avoid cracking during moulding. The compression-moulding cycle consisted of a drying, a compacting and a cooling phase using a maximum pressure of $40 \mathrm{bar}$ at $140^{\circ} \mathrm{C}$ and resulted in panels with a nominal thickness of around $8 \mathrm{~mm}$.

\subsection{Characterisation of binderless all-cellulose composite panels}

Three-point bending tests on the panels were performed using an Instron 5584 universal tester at room temperature with a $1 \mathrm{kN}$ load cell. The cross-head speed was $5 \mathrm{~mm} / \mathrm{min}$. In order to account for the potential anisotropic behaviour of the panels, specimens were cut into strips $(25 \mathrm{~mm} \times 160 \mathrm{~mm})$ in both longitudinal and transverse directions according to the ASTM D790-02 ${ }^{42}$ standard (procedure A) (Figure 3(a)). At least eight specimens of each sample were tested (Figure 3(b)), and values were averaged.

The microstructure of the binderless all-cellulose composites was analysed by scanning electron microscopy (SEM), using a Jeol JSM 6300 microscope at an accelerating voltage of $10 \mathrm{kV}$. Prior to examination, the surface of the samples was sputtered with a thin layer of gold to make them conductive.

The density of the all-cellulose panels was measured directly by weighing the hot-pressed panels. Porosity can then be calculated from the measured density following the equation

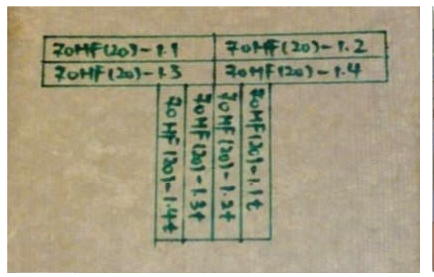

(a)

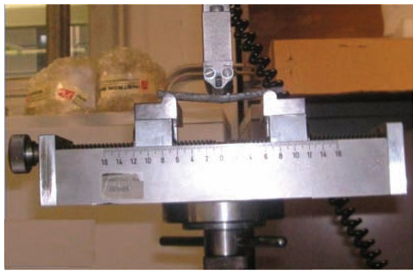

(b)
Figure 3. (a) Image of an all-cellulose panel showing the location of test samples cut in both longitudinal and transverse directions according to the ASTM D 790-02 standard (procedure A);

(b) image of an all-cellulose composite sample subjected to a three-point bending test

1. $\operatorname{porosity}(\%)=\left(\rho_{\mathrm{c}}-\rho_{\mathrm{p}}\right) / \rho_{\mathrm{c}} \times 100$

where $\rho_{\mathrm{c}}$ is the density of cellulose $\left(1.6 \mathrm{~g} / \mathrm{cm}^{3}\right)$ and $\rho_{\mathrm{p}}$ corresponds to the density of the panel.

The WA of the best-performing binderless all-cellulose composite panels was monitored at regular intervals. Prior to carrying out these tests, the samples were dried in an oven at $60^{\circ} \mathrm{C}$ until a constant mass. The dried specimens were then submerged in a Grant Y-38 distilled water bath at $23^{\circ} \mathrm{C}$, removed, wiped dry with a paper towel and weighed using a high-precision balance at selected time intervals. The WA was determined from the weight differences using the following equation

2. $\mathrm{WA}(\%)=\left(W_{\mathrm{w}}-W_{\mathrm{d}}\right) / W_{\mathrm{d}} \times 100$

where $W_{\mathrm{w}}$ and $W_{\mathrm{d}}$ are the weight of wet and dry samples, respectively. Times ranging from 0 to $48 \mathrm{~h}$ were studied.

\section{Results and discussion}

First, the refinement of pure kraft fibres in the Valley beater was studied separately in order to characterise the level of fibrillation and morphology as a function of the refinement time. Before actual refinement, the kraft paper was first disintegrated in the Valley beater. The final degree of fibrillation of the kraft fibres was determined by the SR method for different refinement times, as shown in Figure 4. For the first 15 min of refining, only a slight increase in the degree of fibrillation of the kraft fibres can be observed. However, a further increase in refinement time leads to a drastic improvement in the ${ }^{\circ} \mathrm{SR}$ value, indicating greater fibre fibrillation. The morphology of the kraft fibres as a function of refinement time as observed by optical microscopy (OM) is presented in Figure 5. The OM images clearly support the results obtained through the SR method, evidencing that effective microfibrillation is obtained only after $15 \mathrm{~min}$ of refinement. This implies that effective inter-fibre bonding between kraft fibres and recycled paper may be achieved only after $15 \mathrm{~min}$ of refinement. 


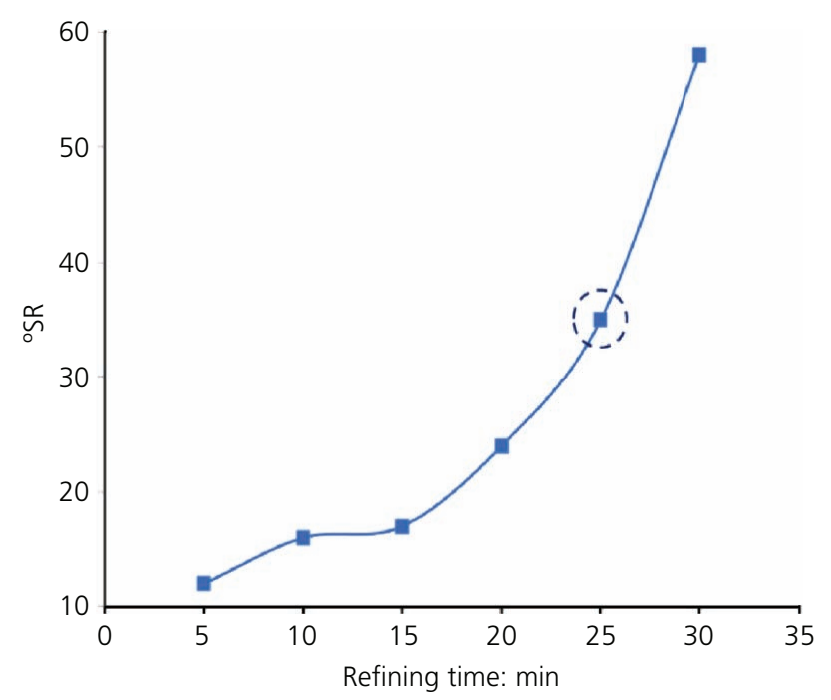

Figure 4. Effect of the refinement time on the ${ }^{\circ} \mathrm{SR}$ value of kraft fibre pulp. The optimum level of microfibrillation of the kraft fibres for the production of self-binding kraft/recycled paper composites - as will be shown later - is encircled

It is worth highlighting that $30 \mathrm{~min}$ of refining leads to excessive fibrillation and damage of the kraft fibres, with little remaining of the original kraft fibre microstructure (Figure 5(f)).

Next, the influence of refinement time on the physical properties of the hot-pressed all-cellulose composite panels was studied. Again, kraft paper was first disintegrated in the Valley beater before wet recycled paper was added for final refinement of the blend in the Valley beater for different periods of time. The influence of refinement time on the flexural properties of the kraft fibre/recycled paper composites $(30 / 70 \mathrm{wt} . \%$ ratio) is shown in Figure 6. As expected from the separate kraft fibrillation studies, the effect of microfibrillation on the flexural properties of the selfbinding kraft fibre/recycled paper composites was not evident up to $15 \mathrm{~min}$ of refinement, after which a strong improvement of both flexural modulus and flexural strength was observed. A further increase in refinement times leads to a drastic improvement in microfibrillation, as shown in Figures 4 and 5, explaining the sudden improvement in composite properties for refinement times of 20 and $25 \mathrm{~min}$. This sudden enhancement of panel properties is associated with an increase in panel density from around $1 \cdot 15-1 \cdot 20 \mathrm{~g} / \mathrm{cm}^{3}$ for panels with refinement times of up to $15 \mathrm{~min}$ and densities of $1.35 \mathrm{~g} / \mathrm{cm}^{3}$ for panels with refinement times of $\geq 20 \mathrm{~min}$. At $25 \mathrm{~min}$ of refinement time, the flexural properties reach maximum values of $5.9 \mathrm{GPa}$ and $75 \mathrm{MPa}$ for stiffness and strength, respectively. Compared with the values for conventional panel board products such as oriented strand board (OSB) or medium-density fibreboard (MDF) and wood fibre plastic (WFP) or NFRP, these values are very favourable. ${ }^{43,44}$ The current low-cost binder-free all-cellulose composites show a slightly higher or comparable stiffness but significantly greater strength compared with OSB, MDF, WFP or NFRP with typical strength values ranging from 20 to $50 \mathrm{MPa} .^{15,43,44}$ The lower strength of conventional panel board materials can again be linked to the relatively low density of such panels. Typical board densities for MDF are $0 \cdot 4-0.8 \mathrm{~g} / \mathrm{cm}^{3}$ and that for OSB is $0.7 \mathrm{~g} / \mathrm{cm}^{3}$, significantly lower than those for the microfibrillated allcellulose composite panels.

Compared with the authors' previously reported self-binding allcellulose composites based on $100 \%$ microfibrillated flax fibres, ${ }^{15}$ the current composites have slightly weaker mechanical properties. Flax-fibre-based self-binding all-cellulose panels based on fibres with optimised fibre lengths exhibited a maximum panel density of $1.41 \mathrm{~g} / \mathrm{cm}^{3}$ and maximum flexural strength and modulus of $120 \mathrm{MPa}$ and $17 \mathrm{GPa},{ }^{20}$ respectively, compared with values of $1.35 \mathrm{~g} / \mathrm{cm}^{3}, 75 \mathrm{MPa}$ and $5.9 \mathrm{GPa}$ for the current panels,
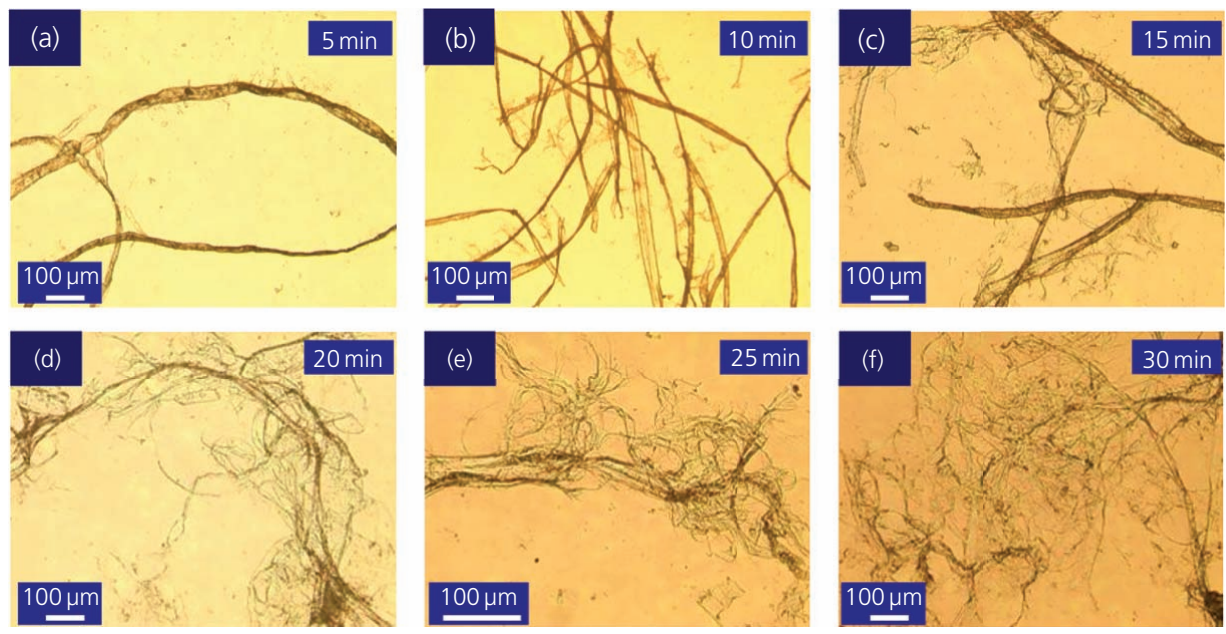

Figure 5. Effect of refinement time on the morphology of microfibrillated kraft fibres. The OM images show kraft fibres refined in a Valley beater for (a) 5, (b) 10, (c) 15, (d) 20, (e) 25 and (f) 30 min 


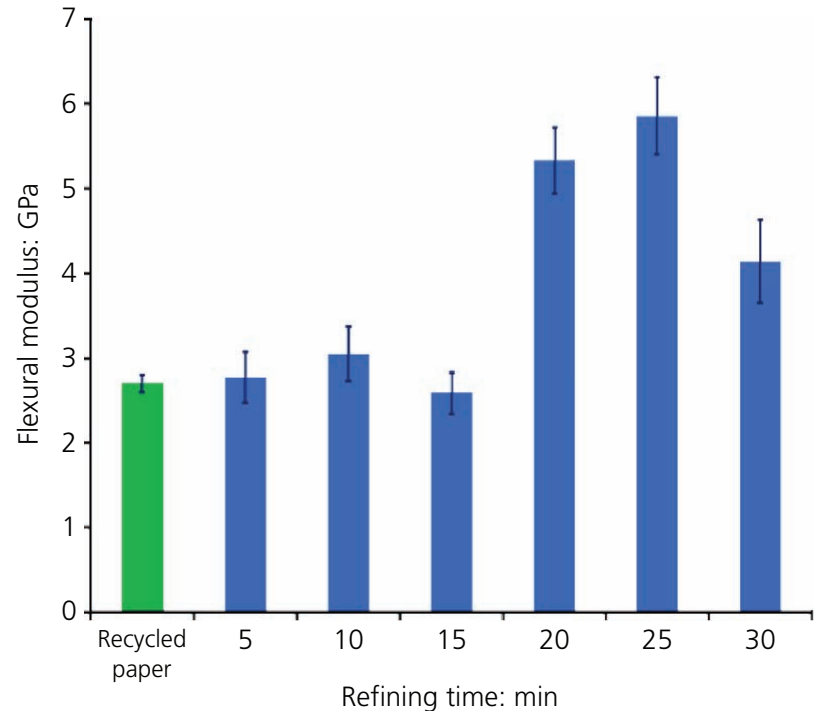

(a)

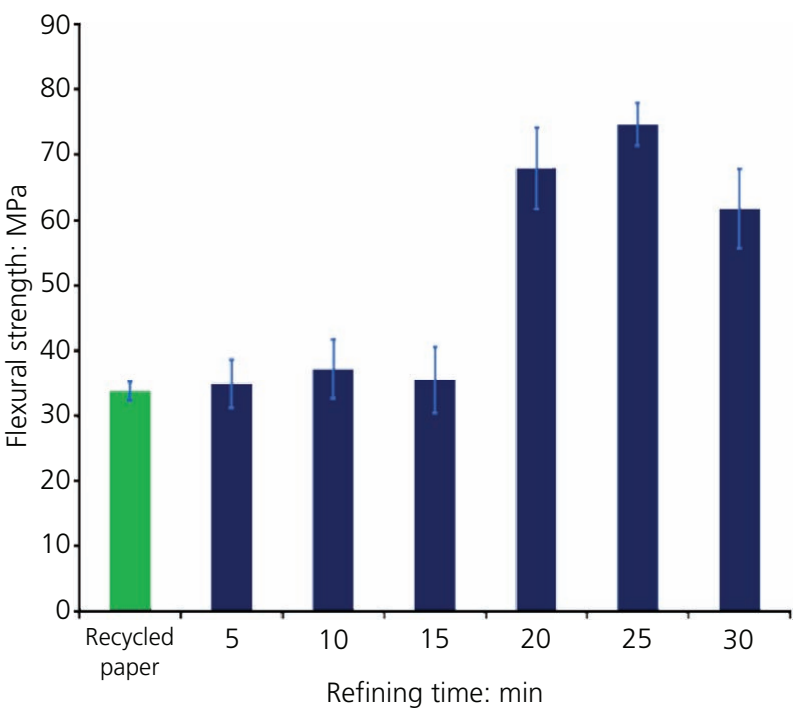

(b)

Figure 6. Effect of refinement time of kraft fibre/recycled paper (30/70 w/w) blend on the (a) flexural modulus and (b) flexural strength of dewatered and hot-pressed binderless recycled paper composites reinforced with $30 \mathrm{wt}$. \% bleached kraft fibres. For comparison, the mechanical properties of materials made solely from recycled paper are also included (green bars)

respectively - that is, a $65 \%$ and a $37 \%$ reduction in mechanical properties. However, from a circular economy and raw material cost point of view, the current panels are still of great interest. The recycled-paper-based composites have significant environmental benefits, as they are based on waste stream materials that are upgraded into a high-quality construction material. Moreover, this material can again be recycled in principle into all-cellulose panels or other paper-based products. Likewise, the current all-cellulose composite materials may have some significant cost advantages, as they are $70 \%$ based on recycled paper and 30\% kraft paper, both of which are considerably cheaper than flax fibres. Based on an estimated price for recycled paper of $€ 0 \cdot 10 / \mathrm{kg}$ and $€ 1 / \mathrm{kg}$ for kraft paper, the raw material price of the blend works out at $€ 0 \cdot 37 / \mathrm{kg}$, which is significantly less $(78 \%)$ than that of flax fibres with an estimated price of $€ 1 \cdot 7 / \mathrm{kg}^{45}$

Excessive fibrillation and damage of the kraft fibres ( ${ }^{\circ} \mathrm{SR}$ value of 58) after 30 min of refining lead to a significant loss of reinforcing efficiency. The optimum degree of fibrillation of kraft fibres for use as reinforcements in recycled-paper-based composites corresponds to an ${ }^{\circ} \mathrm{SR}$ value of around 35 and was achieved after a refining time of $25 \mathrm{~min}$ in a Valley beater (see Figure 4).

The sudden improvement in the mechanical properties of the kraft fibre/recycled paper composites after $15 \mathrm{~min}$ of refinement could be attributed to the difficulty of re-pulping the once-dried bleached kraft pulp due to the strong hydrogen bonding established between kraft fibres during drying. ${ }^{46}$ Gurnagul et al. ${ }^{47}$ studied the physical properties and response to refining of neverdried and dried kraft pulps and reported that never-dried pulps require less energy to reach a certain degree of fibrillation due to greater swelling and conformability of never-dried fibres. Therefore, pulps should be dried only if they need to be stored or transported, as in this case. In addition, the removal of hemicellulose results in the replacement of relatively flexible cellulose-hemicellulose-cellulose bonds by more rigid cellulose-cellulose bonds, thus increasing the refining energy required for a given degree of fibrillation. ${ }^{48}$ Therefore, the results suggest that effective fibrillation of dried bleached kraft fibres starts only after $15 \mathrm{~min}$ refining.

In an attempt to achieve a better understanding of the mechanical behaviour as a function of refinement time, the fracture surfaces of the kraft fibre/recycled paper composites were analysed by SEM, using a Jeol JSM 6300 microscope at an accelerated voltage of $10 \mathrm{kV}$ (Figure 7). The SEM images corresponding to the kraft fibre/ recycled paper composites obtained after $5 \mathrm{~min}$ (Figure 7(a)) and $10 \mathrm{~min}$ (Figure 7(b)) of refining indicate that the fibrillation process has not yet started, thus preventing good inter-fibre bonding between the kraft and paper fibres. After a refinement time of $15 \mathrm{~min}$, a few fibrils appear on the kraft fibre surfaces; however, large voids around these fibres indicate that this degree of fibrillation is still insufficient for achieving effective kraft fibre-recycled paper cross-linking (Figure 7(c)). A further $5 \mathrm{~min}$ refining results in an enhancement of the kraft fibre specific surface area (Figure 7(d)), allowing for an increase in fibre-fibre interactions, enhanced cellulose network formation, better consolidation and improved mechanical properties. However, also here the presence of non-fibrillated kraft fibres can still be observed. A highly densified structure, consisting of highly microand nanofibrillated kraft fibres surrounded by recycled paper fibres, 

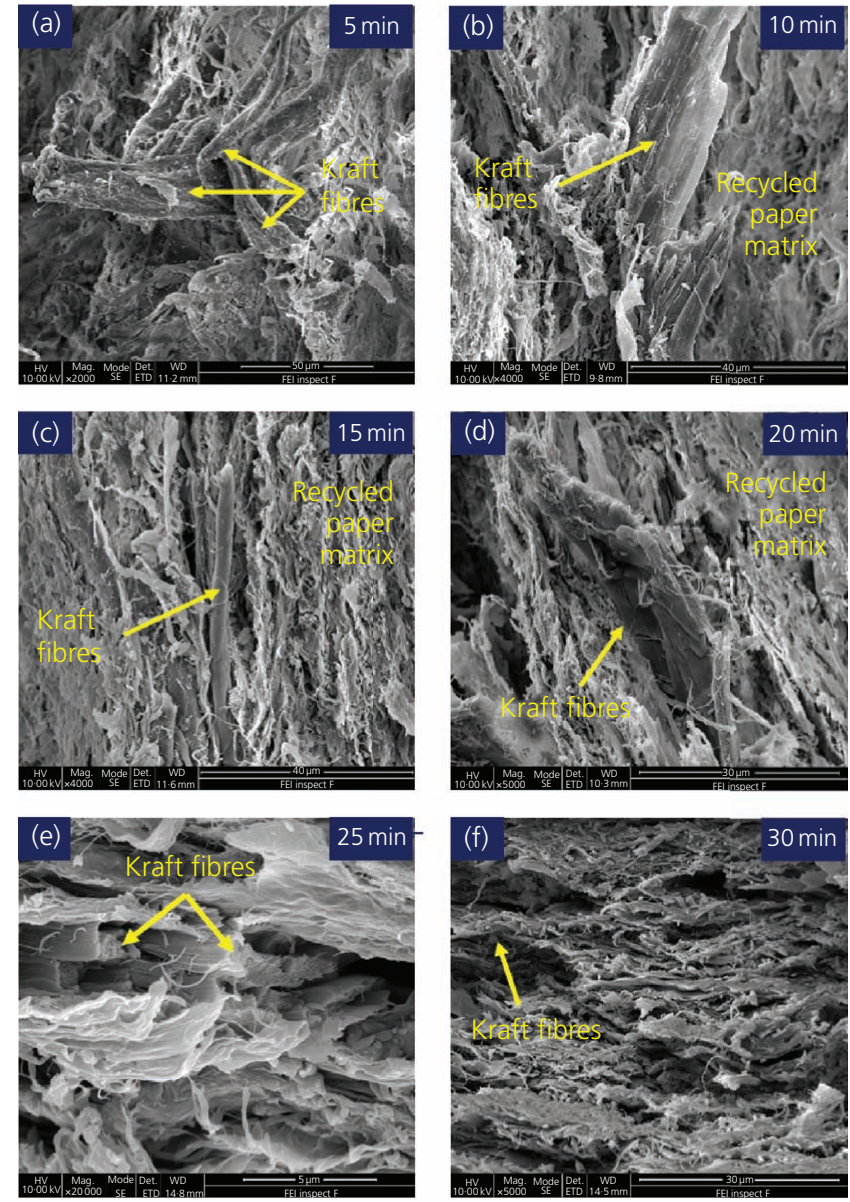

Figure 7. SEM images of fracture surfaces of binderless recycledpaper-based composites reinforced with $30 \mathrm{wt}$ \% kraft fibres refined for (a) 5, (b) 10, (c) 15, (d) 20, (e) 25 and (f) $30 \mathrm{~min}$. Arrows indicate the presence of kraft fibres in the recycled paper matrix

is achieved only after $25 \mathrm{~min}$ of mechanical refining (Figure 7(e)). At this refinement time, the level of fibrillation of the kraft fibres is sufficient to render strong inter-fibre network formation while still preserving their fibrous microstructure and reinforcing ability, thus leading to an optimal combination of inter-fibre adhesion by the micro- and nanofibrillated network and intrinsic reinforcement by the kraft microfibrils. SEM images of kraft fibre/recycled paper composites obtained after $30 \mathrm{~min}$ of mechanical refining (Figure 7(f)) show excessive fibrillation, as well as great microstructural damage and destruction of the kraft fibre structure and aspect ratio, leading to a loss of the intrinsic reinforcing efficiency and weakening of composite properties. The distinction between kraft fibres and recycled paper fibres in this composite structure becomes less clear due to the high degree of fibrillation of the kraft fibres.

Finally, the WA behaviour of well-compacted binder-free kraft fibre/recycled paper composite panels was studied at regular intervals (Figure 8). Moisture absorption of cellulose-based materials is clearly a concern for durable engineering applications.

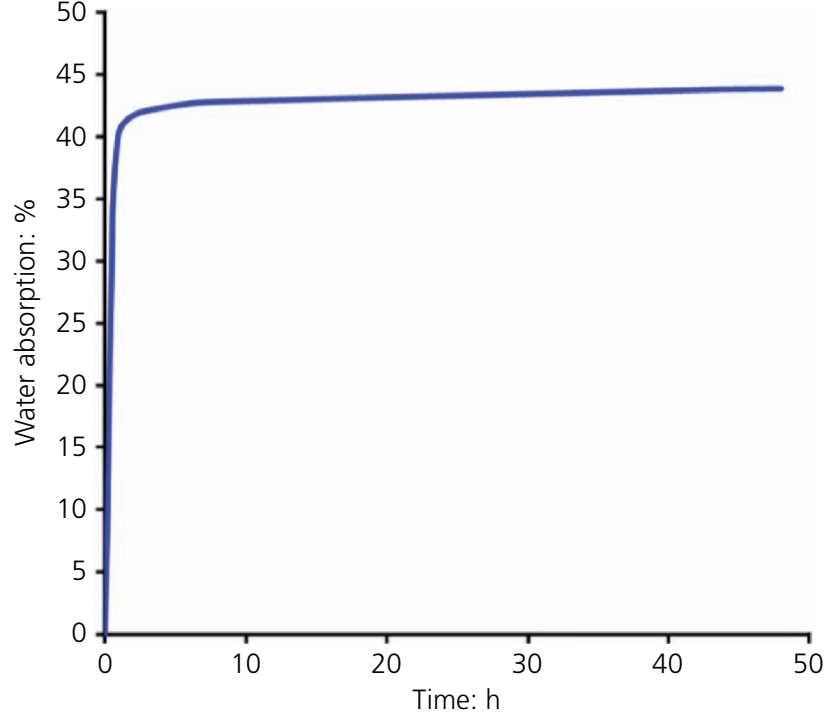

Figure 8. WA of binderless recycled paper composite reinforced with 30 wt. \% kraft fibres refined for 25 min

This is particularly the case for all-cellulose composites, as here protection by a polymer matrix as in the case of wood- or naturalfibre-reinforced plastics is absent. ${ }^{49}$ For this study, a welldensified composite panel with optimal mechanical properties was selected. Based on a panel density of $1.35 \mathrm{~g} / \mathrm{cm}^{3}$ and a cellulose density of $1.6 \mathrm{~g} / \mathrm{cm}^{3}$, the porosity content of this panel was estimated using Equation 2 to be $16 \%$.

The initial WA of the panels is very rapid, with saturation occurring after some $6 \mathrm{~h}$ of immersion, and involves the absorption of water by both pores and cell walls. The fibre saturation point (FSP) of wood fibres is around $25 \%$. Below the FSP, all moisture is considered to be absorbed exclusively by the cell walls, whereas, above the FSP, moisture is exclusively accommodated in empty pores or capillaries. ${ }^{50}$ When the panels reach $43 \%$ WA at equilibrium, this means that $18 \%$ of the weight is water in pores, whereas $25 \%$ is absorbed by the cell walls. These estimates are in good agreement with the calculated porosity of the panel of $16 \%$. Once the pores and cell walls are saturated with water, the WA is significantly reduced, leading to an almost constant weight and a water saturation level of $43 \%$. This level of WA is, as expected, higher than that of a typical NFRP, such as polypropylene/flax $(\sim 20 \%$ WA $){ }^{51}$ where lignocellulosic fibres are protected by a hydrophobic polymer matrix, but still lower than those of most conventional wood panel products, such as OSB (75\% WA), ${ }^{51}$ MDF $(65 \% \mathrm{WA})^{52}$ and compressed pine wood panels $(55 \% \mathrm{WA}){ }^{53}$ This is particularly impressive, as here the entire material is made from cellulose and there is no polymer resin present to bind or protect the fibres. The WA of the current composite panels is also only slightly higher than those reported previously for panels based on $100 \%$ microfibrillated flax fibres (37\% WA). WA in both types of all-cellulose panels is strongly dominated by porosity and disordered cellulose regions, suggesting that these parameters are 
not too dissimilar for both flax-fibre-based and kraft/recycled-paperbased panels. The relatively low moisture absorption of the current kraft/recycled paper composite panels can again be directly related to the highly dense microstructure of compression-moulded microfibrillated cellulose fibres, leading to significantly lower porosity levels compared with conventional panel board products.

\section{Conclusions}

Potentially low-cost binder-free all-cellulose composite panels were successfully produced using recycled paper as a matrix reinforced with $30 \mathrm{wt} . \%$ kraft fibres. Processing involved the mechanical refinement of cellulose fibres using an environmentally friendly processing method with only water as a processing aid. Surface fibrillation of the kraft fibres increased their specific surface area, thus allowing for greater inter-fibre interactions, improved cellulose network formation and better densification of the hot-pressed composite panels. The addition of $30 \mathrm{wt} . \%$ optimally refined kraft fibre reinforcements into a recycled paper pulp matrix led to greatly improved mechanical properties of these all-cellulose composite panels. Optimal micro- and nanofibrillation of the kraft fibres was crucial for achieving a good balance between self-binding and reinforcing efficiency of these fibres in the recycled paper matrix. Kraft fibres with a low degree of fibrillation did not possess a sufficient specific surface area to create a strong bond with the recycled paper pulp matrix, leading to poor compaction and low mechanical performance. Conversely, excessive refinement times resulted in the loss of reinforcing efficiency as a result of destruction of the internal kraft fibre structure as well as reduced aspect ratio. An optimum degree of fibrillation of the kraft fibres was achieved at a drainage resistance ${ }^{\circ} \mathrm{SR}$ value of 35 and was reached after 25 min of mechanical refinement in a Valley beater. In summary, the addition of $30 \mathrm{wt} . \%$ kraft fibres to recycled paper pulp did result in a $123 \%$ improvement in panel strength (75 MPa) and a $119 \%$ increase in panel stiffness $(5.9 \mathrm{GPa})$ compared with pure recycled-paper-based panels. The mechanical properties of these fully biobased panels still outperformed many conventional panel board products and wood- or natural-fibre-reinforced plastics. Since these materials mainly use waste streams rather than more expensive lignocellulosic fibre streams, the current approach could lead to highly cost-effective green panel products that can compete with or outperform existing products. Moreover, as these materials are in principle recyclable using a simple re-pulping process or compostable, they should fit well in a circular economy.

\section{Acknowledgement}

This work was carried out as part of the Reflect project funded by Innovate UK in the UK.

\section{REFERENCES}

1. Peijs T (2000) Natural fiber based composites. Materials Technology 15(4): 281-285.

2. Berglund LA and Peijs T (2010) Cellulose biocomposites - from bulk moldings to nanostructured systems. MRS Bulletin 35(3): 201-207.

3. Zafeiropoulos NE (ed.) (2011) Interface Engineering of Natural Fibre Composites for Maximum Performance. Woodhead, Oxford, UK.
4. Madsen B, Thygesen A and Lilholt H (2007) Plant fibre composites porosity and volumetric interaction. Composites Science and Technology 67(7-8): 1584-600.

5. Nishino T and Peijs T (2014) All-cellulose composites. In Handbook of Green Materials: Biomaterials: Separation Processes, Characterization and Properties (Oksman K, Mathew AP, Bismarck A, Rojas O and Sain M (eds)). World Scientific, Hackensack, NJ, USA, pp. 201-216.

6. Eichhorn SJ, Dufresne A, Aranguren M et al. (2010) Current international research into cellulose nanofibres and nanocomposites. Journal of Materials Science 45(1): 1-33.

7. Nishino T and Arimoto N (2007) All-cellulose composite prepared by selective dissolving of fiber surface. Biomacromolecules $\mathbf{8 ( 9 )}$ : 2712-2716.

8. Qin C, Soykeabkaew N, Xiuyuan N and Peijs T (2008) The effect of fibre volume fraction and mercerization on the properties of allcellulose composites. Carbohydrate Polymers 71(3): 458-467.

9. Soykeabkaew N, Arimoto N, Nishino T and Peijs T (2008) Allcellulose composites by surface selective dissolution of aligned lignocellulosic fibres. Composites Science and Technology 68(10-11): 2201-2207.

10. Soykeabkaew N, Sian C, Gea S, Nishino T and Peijs T (2009) Allcellulose nanocomposites by surface selective dissolution of bacterial cellulose. Cellulose 16(3): 435-444.

11. Arévalo R, Picot OT, Wilson RM, Soykeabkaew N and Peijs T (2010) All-cellulose composites by partial dissolution of cotton fibres. Journal of Biobased Materials and Bioenergy 4(2): 129-138.

12. Iguchi M, Yamanaka S and Budhiono A (2000) Bacterial cellulose - a masterpiece of nature's arts. Journal of Materials Science 35(2): 261-270.

13. Gea S, Reynolds CT, Roohpour N et al. (2011) Investigation into the structural, morphological, mechanical and thermal behaviour of bacterial cellulose after a two-step purification process. Bioresource Technology 102(19): 9105-9110.

14. Henriksson $M$, Berglund LA, Isaksson $P$, Lindstrom $T$ and Nishino $T$ (2008) Cellulose nanopaper structures of high toughness. Biomacromolecules 9(6): 1579-1585.

15. Arévalo R and Peijs T (2016) Binderless all-cellulose fibreboard from microfibrillated lignocellulosic natural fibres. Composites Part A: Applied Science and Manufacturing 83: 38-46.

16. Fahmy TY and Mobarak F (2013) Advanced binderless board-like green nanocomposites from undebarked cotton stalks and mechanism of self-bonding. Cellulose 20(3): 1453-1457.

17. Nilsson H, Galland S, Larsson PT et al. (2010) A non-solvent approach for high-stiffness all-cellulose biocomposites based on pure wood cellulose. Composites Science and Technology 70(12): 1704-1712.

18. Yousefi H, Azad S, Mashkour M and Khazaeian A (2018) Cellulose nanofiber board. Carbohydrate Polymers 187: 133-139.

19. Anglès MN, Reguant J, Montané D et al. (1999) Binderless composites from pretreated residual softwood. Journal of Applied Polymer Science 73(12): 2485-2491.

20. Bouajila J, Limare A, Joly C and Dole P (2005) Lignin plasticization to improve binderless fiberboard mechanical properties. Polymer Engineering \& Science 45(6): 809-816.

21. Quintana G, Velasquez J, Betancourt S and Ganan P (2009) Binderless fiberboard from steam exploded banana bunch. Industrial Crops and Products 29(1): 60-66.

22. Diop CIK, Tajvidi M, Bilodeau MA, Bousfield DW and Hunt JF (2017) Evaluation of the incorporation of lignocellulose nanofibrils as sustainable adhesive replacement in medium density fiberboards. Industrial Crops and Products 109: 27-36.

23. Diop CIK, Tajvidi M, Bilodeau MA, Bousfield DW and Hunt JF (2017) Isolation of lignocellulose nanofibrils (LCNF) and application as adhesive replacement in wood composites: example of fibreboard. Cellulose 24(7): 3037-3050. 
24. Pink S, Veigel S, Colson J and Gindl-Altmutter W (2017) Nanopaper properties and adhesive performance of microfibrillated cellulose from different (ligno-)cellulosic raw materials. Polymers 9(8): 326-338.

25. Tayeb AH, Amini E, Ghasemi S and Tajvidi M (2018) Cellulose nanomaterials - binding properties and applications: a review. Molecules 23(10): 2684-2708.

26. Sun W, Tajvidi M, Hunt CG, McIntyre G and Gardner DJ (2019) Fully bio-based hybrid composites made of wood, fungal mycelium and cellulose nanofibrils. Scientific Reports 9(1): 3766-3779.

27. Shivyari NY, Tajvidi M, Bousfield DW and Gardner DJ (2016) Production and characterization of laminates of paper and cellulose nanofibrils. ACS Applied Materials \& Interfaces 8(38): 25520-25528.

28. Tajvidi M, Gardner DJ and Bousfield DW (2016) Cellulose nanomaterials as binders: laminate and particulate systems. Journal of Renewable Materials 4(5): 365-376.

29. Wistara N and Young RA (1999) Properties and treatments of pulps from recycled paper. Part I. Physical and chemical properties of pulps. Cellulose 6(4): 291-324.

30. Hubbe MA, Venditti RA and Rojas OJ (2007) What happens to cellulosic fibers during papermaking and recycling? A review. BioResources 2(4): 739-788.

31. Wanrosli WD, Zainuddin Z and Roslan S (2005) Upgrading of recycled paper with oil palm fiber soda pulp. Industrial Crops and Products 21(3): 325-329.

32. Minor JL, Atalia RH and Harten TM (1993) Improving interfibre bonding of recycled fibres. Journal of Pulp and Paper Science 19(4): J152-J155

33. Ahmad AM, Jalaluddin H, Paridah MT et al. (2010) A review of literatures related of using kenaf for pulp production (beating, fractionation, and recycled fiber). Modern Applied Science 4(9): 21-29.

34. Ellis RL and Sedlachek K (1993) Recycled vs. virgin fiber characteristics: a comparison. TAPPI Journal 76(2): 143

35. Mao R, Goutianos S, Tu W et al. (2017) Modelling the elastic properties of cellulose nanopaper. Materials \& Design 126: 183-189.

36. Mao R, Goutianos S, Tu W et al. (2017) Comparison of fracture properties of cellulose nanopaper, printing paper and buckypaper. Journal of Materials Science 52(16): 9508-9519.

37. Goutianos S, Mao R and Peijs T (2018) Effect of inter-fibre bonding on the fracture of fibrous networks with strong interactions. International Journal of Solids and Structures 136: 271-278.

38. Howard RC (1990) The effects of recycling on paper quality. Journal of Pulp and Paper Science 16(5): J143-J149.

39. Goutianos S, Arévalo R, Sørensen BF and Peijs T (2014) Effect of processing conditions on fracture resistance and cohesive laws of binderfree all-cellulose composites. Applied Composite Materials 21(6): 805-825.

40. BSI (1981) BS 6035-1:1981: Methods for determination of the drainability of pulp. Schopper-Riegler method. BSI, London, UK.

41. ISO (1999) 5267-1: Pulps - determination of drainability - part 1: Schopper-Reigler method. ISO, Geneva, Switzerland.

42. ASTM (2002) D790-02: Standard test methods for flexural properties of unreinforced and reinforced plastics and electrical insulating materials. ASTM International, West Conshohocken, PA.

43. Jiang $\mathrm{H}$ and Kamdem DP (2004) Development of poly(vinyl chloride)/wood composites: a literature review. Journal of Vinyl and Additive Technology 10(2): 59-69.

44. Taha I and Ziegmann G (2006) A comparison of mechanical properties of natural fiber filled biodegradable and polyolefin polymers. Journal of Composite Materials 40(21): 1933-1946.

45. Bourmaud A, Beaugrand J, Shah DU, Placet V and Baley C (2018) Towards the design of high-performance plant fibre composites: how can we best define the diversity and specificities of plant cell walls? Progress in Materials Science 97: 347-408.

46. Abe K, Iwamoto $S$ and Yano H (2007) Obtaining cellulose nanofibers with a uniform width of $15 \mathrm{~nm}$ from wood. Biomacromolecules $8(\mathbf{1 0})$ 3276-3278.

47. Gurnagul N, Page DH and Seth RS (1990) Dry sheet properties of Canadian hardwood kraft pulps. Journal of Pulp and Paper Science 16(1): 36-41.

48. Pande H and Roy DN (1998) Influence of fibre morphology and chemical composition on the papermaking potential of kenaf fibres. Pulp \& Paper Canada 99(11): 31-34.

49. Stamboulis A, Baillie CA, Garkhail SK, Van Melick HG and Peijs T (2000) Environmental durability of flax fibres and their composites based on polypropylene matrix. Applied Composite Materials 7(5-6): 273-294.

50. Engelund ET, Thygesen LG, Svensson S and Hill CA (2013) A critical discussion of the physics of wood-water interactions. Wood Science and Technology 47(1): 141-161.

51. Kirkpatrick JW and Barnes HM (2006) Copper naphthenate treatments for engineered wood composite panels. Bioresource Technology 97(15): 1959-1963.

52. Zheng Y, Pan Z, Zhang R, Jenkins BM and Blunk S (2006) Properties of medium-density particleboard from saline Athel wood. Industrial Crops and Products 23(3): 318-326.

53. Unsal O, Kartal SN, Candan Z et al. (2009) Decay and termite resistance, water absorption and swelling of thermally compressed wood panels. International Biodeterioration \& Biodegradation 63(5): 548-552.

\section{How can you contribute?}

To discuss this paper, please submit up to 500 words to the journal office at journals@ice.org.uk.Your contribution will be forwarded to the author(s) for a reply and, if considered appropriate by the editor-in-chief, it will be published as a discussion in a future issue of the journal.

ICE Science journals rely entirely on contributions from the field of materials science and engineering. Information about how to submit your paper online is available at www.icevirtuallibrary.com/page/authors, where you will also find detailed author guidelines. 